\title{
Career Cartography: From Stories to Science and Scholarship
}

\author{
Deleise S. Wilson, PhD, RN ${ }^{1}$, Marie-Anne S. Rosemberg, PhD, RN ${ }^{2}$, Moira Visovatti, PhD, $\mathrm{RN}^{3}$, \\ Michelle L. Munro-Kramer, PhD, CNM, FNP-BC ${ }^{4}$, \& Suzanne Feetham, PhD, RN, FAAN ${ }^{5,6}$ \\ 1 Rho, Professor, Director, Division of Nursing, Kettering College, Kettering, OH, USA \\ 2 Psi, Assistant Professor, University of Michigan, School of Nursing, Ann Arbor, MI, USA \\ 3 Rho, Assistant Professor, University of Michigan, School of Nursing, Ann Arbor, MI, USA \\ 4 Rho, Assistant Professor, University of Michigan, School of Nursing, Ann Arbor, MI, USA \\ 5 Lamda, Professor, Emerita University of Illinois at Chicago \\ 6 Lamda, Nursing Research Consultant, Children's National Health System, Washington, DC, USA
}

\begin{abstract}
Key words
Career cartography, gender issues administration, gynecology, health of specific populations, mentorship, patient safety administration, professional ethics, professional issues, professional standards, public policy, women's health
\end{abstract}

\section{Correspondence}

Dr. Deleise S. Wilson, Division of Nursing, Kettering College, 3737 Southern Blvd,

Kettering, Ohio 45429. E-mail:

Deleise.Wilson@kc.edu

Accepted January 26, 2017

doi: 10.1111/jnu.12289

\begin{abstract}
Purpose: To present four case scenarios reflecting the process of research career development using career cartography.

Organizing Constructs: Career cartography is a novel approach that enables nurses, from all clinical and academic settings, to actively engage in a process that maximizes their clinical, teaching, research, and policy contributions that can improve patient outcomes and the health of the public.

Methods: Four early-career nurse researchers applied the career cartography framework to describe their iterative process of research career development. They report the development process of each of the components of career cartography, including destination statement, career map, and policy statement.

Conclusions: Despite diverse research interests and career mapping approaches, common experiences emerged from the four nurse researchers. Common lessons learned throughout the career cartography process include: (a) have a supportive mentorship team, (b) start early and reflect regularly, (c) be brief and to the point, (d) keep it simple and avoid jargon, (e) be open to change, (f) make time, and (g) focus on the overall career destination.

Clinical Relevance: These four case scenarios support the need for nurse researchers to develop their individual career cartography. Regardless of their background, career cartography can help nurse researchers articulate their meaningful contributions to science, policy, and health of the public.
\end{abstract}

Career cartography, also known as career planning, career mapping, or legacy mapping, refers to creating a visual depiction of long-term career goals and the steps or processes necessary to meet those goals (Messmer, 2003). As described by Feetham and Doering (2015), career cartography is "the science of designing, drawing, communicating, and producing a map to guide researchers toward their intended career destination" (p. 71). This concept is currently utilized within the disciplines of business, finance, and the broader realm of health care to help individuals and their mentors chart a pathway to success. Career cartography has also been identified as a tool to help an individual attain work meaning (Hinds et al., 2015). In this sense, career cartography becomes a tool to help individuals take ownership of their success and attain work meaning (Hader, 2005; Hinds et al., 2015). As such, it has been described as a tool to help an individual achieve purpose and meaningful work engagement as opposed to the more routine aims of promotion or achieving a leadership position (Hinds et al., 2015). For nursing, career cartography may also move the discipline and science forward as practitioners, educators, administrators, and researchers thoughtfully plan and achieve personal goals that benefit individual patients, communities, or populations. However, this article is an exemplar of using the career cartography process for nursing researchers.

Early-career nursing scientists enter their academic positions with a multitude of responsibilities, including 
teaching, mentoring, research, clinical practice, and service (Brody et al., 2016). These competing demands are difficult to juggle as the faculty member is often teaching classes for the first time while trying to obtain funding and publishing. This often leads the junior faculty member to "try to make it through the day" without considering their long-term career and research goals (Hofler \& Thomas, 2016). Past research indicates that professional development opportunities such as mentoring, institutional support, and role modeling provide opportunities for professional growth and success in nursing science (Boyden, 2000; Drummond-Young et al., 2010; Hofler \& Thomas, 2016). Another method of providing this professional direction, development, and growth is using the career cartography process.

As nurses consider their professional roles and chart their individual career paths, it is imperative that they reflect on how they want to contribute to the discipline of nursing while working to improve the lives of others. This reflection on the long-term plans helps nurses identify and achieve their professional goals while contributing to a meaningful and satisfying career. For academics, career cartography is an iterative process of visually portraying one's career development that highlights the areas of research, practice, and policy (Feetham \& Doering, 2015). It is essential that nurses incorporate the elements that will help determine their success, which are a clearly written destination statement, identification of relevant policy issues, a visual depiction of their career mapping, a supportive mentorship team, and wide dissemination of their contributions to nursing. The ability to develop a succinct yet compelling depiction of the many facets of a career necessitates deliberate actions to facilitate the career cartography process.

One of the key factors aiding the successful navigation of the career cartography process is the supportive relationships from a team of mentors and sponsors (Feetham \& Doering, 2015; Shirey, 2013). Mentors are individuals with significant experience or knowledge who provide instruction or guidance to others on how to advance in their career (Nies \& Troutman-Jordan, 2012). Mentors can provide support in day-to-day work (sounding board, coach), direction on career challenges, and expertise in content or skills needed for career development (Byrne \& Keefe, 2002; Feetham \& Doering, 2015). Mentors can come from an individual's organization, profession (superiors, peers), or outside the work place (parent, spouse, friend) and may differ depending on the individual's stage of career. Successful early-career professionals tend to have multiple sources of mentors within the organization and profession (van Eck Peluchette \& Jeanquart, 2000). Sponsors are different from mentors and are defined as individuals who can provide access to research, academic, and policy development opportunities for early-career professionals. These opportunities allow for the attainment of salient skills, knowledge, and experience needed for career development (Feetham \& Doering, 2015; Shirey, 2013). Building a career cartography team is important and requires early-career professionals to know their strengths as well as areas in need of further development; have realistic expectations (there is no single perfect mentor); and take responsibility for their own career development by finding mentors and negotiating benefits, taking risks, and learning from their experiences (Wills \& Kaiser, 2012).

The goal of this article is to describe how the authors, four early-career nurse researchers, used the career cartography process as described by Feetham and Doering (2015) to develop individual career maps. Key insights from the process and steps to the career cartography process will be discussed to help guide the career of other researchers.

\section{Career Cartography Components}

According to Feetham and Doering (2015), the career cartography process is composed of four major components. They include a destination statement, identification of the policy context of a career, and a career map.

\section{Destination Statement}

A destination statement captures the significant areas of contribution and the objective of a career in a succinct sentence (Feetham \& Doering, 2015). The destination statement can be likened to the branding of a career so that one's contributions to science and capacity to serve a targeted population over an extended period of time can be highlighted (Kasprzak, 2014). Before a destination statement is crafted, it is necessary to be aware of the compelling policy, political, and scientific mandates relevant to the individual's area of interest (Beck, 2008; Feetham \& Doering, 2015). Destination statements are not limited by the status of the researcher, but instead are built upon a premise that there will be full access to all the resources necessary to attend to the evolving needs of the population or outcome of interest (Feetham $\delta$ Doering, 2015).

Although destination statements represent the main features of one's career, they should be presented in multiple versions to reach a variety of audiences and stakeholders (Green, 2009). For example, knowing how to pitch one's contribution to a policy group will be much different from presenting a job talk that highlights one's contribution to science. However, the different versions of the destination statement must maintain consistency 
in message (Green, 2009). Destination statements should be rehearsed so that they can be given in one or two compelling sentences that give a clear vision of one's career contributions. For this reason, it is also called the "elevator speech" or the "pitch" curriculum vitae (Elsbach, 2003).

\section{Policy Statements}

Policies are defined as "governmental or organizational guidelines about allocations of resources and principles of desired behavior" (Trostle, Bronfman, \& Langer, 1999, p. 104). Knowing the policy context for a program of research is essential, as policy is a primary determinant of health (U.S. Department of Health and Human Services, Office of Disease Prevention and Health Promotion, n.d.). Knowing the policy context enables researchers to identify potential support and barriers to their research. Inclusion of policy statements links research to public health and thus can reach a wider audience. Policies can inform nursing research and evidence-based practice. Research influences change across various levels, including individuals, families, communities, states, nations, and the global world. Thus, a conscious consideration of the relationship between research and policy is essential to demonstrate the link between research, political structures, and sustainable impacts (Villarruel \& Fairman, 2015). Consideration of the policy relevance forces the researcher to be aware of all the stakeholders (i.e., patient, health providers, taxpayers, policymakers, and governmental institutions) involved or influenced by the issue at hand and to describe the impact of their science to these different stakeholders (Bensing, CarisVerhallen, Dekker, Delnoij, \& Groenewegen, 2003).

Development of policy statements in the career cartography process can show promise for higher-level change to address a phenomenon. It can also enable access to funding opportunities given that the subject would be aligned with the priorities of the organizations of interest providing financial support to carry out the research.

\section{Career Maps}

A career map is the physical document that displays the steps, processes, or components necessary to achieve one's career goals. It provides a depiction of an individual's career plan with the "measurable metrics" necessary to achieve that goal (Hinds et al., 2015, p. 212). In this sense, the career map provides the documentation that keeps the nurse or nurse researcher on track to attain his or her goals and can be monitored on a regular basis personally and by mentors, supervisors, or peers.
While the career map is a very useful benchmarking tool (Tin \& Wiwanitkit, 2015), it requires constant attention as it is a fluid document that is continually changing based on evolving career goals, new opportunities (i.e., funding, promotion, new collaborators), or new developments in the science. Despite its fluctuating status, the career map remains inextricably linked to the individual's destination statement, policy context, and feedback from the mentorship team.

\section{Methods}

The authors of this article were all postdoctoral research fellows at the same institution and met as a group on a monthly basis during their postdoctoral research fellowships in order to navigate the career cartography process. Utilizing personal experiences, each author describes their individual process using career cartography with an emphasis on the destination statement, policy context, and career map. These individualized first-person case scenarios are intended to illustrate the career cartography process as it applies to four early-career nurse scientists with very diverse research interests. It illustrates the similarities in the process as well as the unique challenges that each of the authors faced when utilizing the career cartography process.

\section{Four Case Scenarios: Applying Career Cartography to One's Academic Career}

\section{Case Scenario 1: What Is Your North Star?}

Destination statement. After successfully moving through several rounds of interviews for a postdoctoral position, my confidence in obtaining the great opportunity was almost shattered during the final interview by the question, "What is your North Star?" It was clear that I was not being asked to recite the impressive accomplishments listed in my curriculum vitae, which was clearly reviewed before this interview. What was also uncomfortably obvious to me was that I did not know how to effectively connect and communicate my recent successes with significant goals for the future. Hence, it was very appealing when given the chance to be mentored by Dr. Suzanne Feetham and to collaborate with three other postdoctoral fellows to engage in the career cartography process.

The first and probably the most elusive part of the career cartography process is the destination statement. The initial drafts of our destination statements were steeply couched in the specialized language and concepts of our research areas. For example, my destination statement stated "the goal of my research is to implement an 
innovative mindfulness staff ride to reduce falls and fall injuries among hospitalized older adults." There are several limitations in the statement, which only became obvious when reviewing it with my team members and Dr. Feetham. First, the stated goal is "to implement," which describes a singular research activity and not a viable long-term research plan. Second, the phrase, "mindfulness staff ride" used language that was specific to a narrow cross-section of organizational behavior science. The term was not easily translated into a healthcare concept. The difficulty of explaining the staff ride intervention to my postdoctoral peers emphasized the futility of using that term to multiple stakeholders. Third, by only mentioning falls in my destination statement, I inadvertently limited the contribution of my extensive research training to one outcome. Multiple iterations finally produced the statement "My program of research is to reduce hospital-acquired conditions by the implementation of systems-level safety interventions that engage patients, caregivers and healthcare providers."

Policy. Feetham (2011) stresses the importance of knowing the political will for a broad area of research. That knowledge is critical to advance timely and relevant advancements in science. The Deficit Reduction Act of 2005, which requires a quality adjustment of Medicare Severity Diagnosis Related Group payments for preventable hospital-acquired conditions, provided a comprehensive platform of adverse events that included falls and fall injuries. These expectations of Medicare demonstrated the political will to support my program of research.

Career map. I developed my career map according to the stages towards independence of a nurse researcher. The research stages are anchored in a destination statement. The first stage of my career map represents the development of my program of research, which included my doctoral education that focused on patient safety and a postdoctoral fellowship in implementation science. The second stage captures the current work involved in being an early-stage investigator, such as development and testing of a systems-level patient safety intervention and submission of grant proposals to funding agencies relevant to my area of focus. In the third stage, as an independent researcher, my research will extend across multiple outcomes, settings, and samples with the use of a variety of research methods. The career map shown in Figure 1 represents the most current juxtaposition of my destination statement, policy context, and the resulting career map, which will continue to evolve as I progress along my career journey.

\section{Case Scenario 2: The Pathway to Intervention Development}

Destination statement. My first attempt to get organized and identify what my research career focus would be was to meet with my peers, the other postdoctoral researchers in my school of nursing who were grappling with the same issues. We started our year by attending a session on career cartography. We thought this would be a terrific way to be organized and set upon creating our personal career maps. Our first step was to write our destination statements. My first destination statement was wrought with context-specific terminology that was unintelligible to my colleagues. Furthermore, I focused intently on only one intervention and not on how the culmination of my projects would affect science and policy. After discussing the destination statement with my peers and research mentors, it became apparent that revisions were needed and that this might be easiest to do once I visually displayed how my past, current, and future research projects all impacted my long-term scientific goals. My destination statement is "to improve the health outcomes of women and children by increasing reproductive health choices and impacting reproductive health policy changes for vulnerable women of childbearing age in domestic and international contexts."

Policy. After practicing clinically as an advanced practice nurse in women's health, I entered graduate school with a specific phenomenon of interest in mind. I wanted to improve postassault care for sexual assault survivors, specifically those that wanted to "self-treat." This did not mean that I wanted to change the current structures in place for postassault care, but instead that I wanted to find a way to provide survivors with the knowledge and resources they needed to make the best decisions for themselves. I completed my dissertation at the same time that sexual assault on college campuses was gaining national headlines because of poorly handled incidents at some major public universities and due to the passage of the Violence Against Women Reauthorization Act (2013) in 2014. During this time, I also became involved in international work focusing on improving reproductive health and decreasing maternal mortality. My research focused on a number of somewhat controversial policy issues, including reproductive health, sexual assault, maternal mortality, and improving access to care. I quickly realized that I needed to find a way to articulate the intersection of policy in these areas in order to demonstrate where I wanted to make a difference.

Career map. My initial attempt at creating a career map to visually display all of these components consisted 


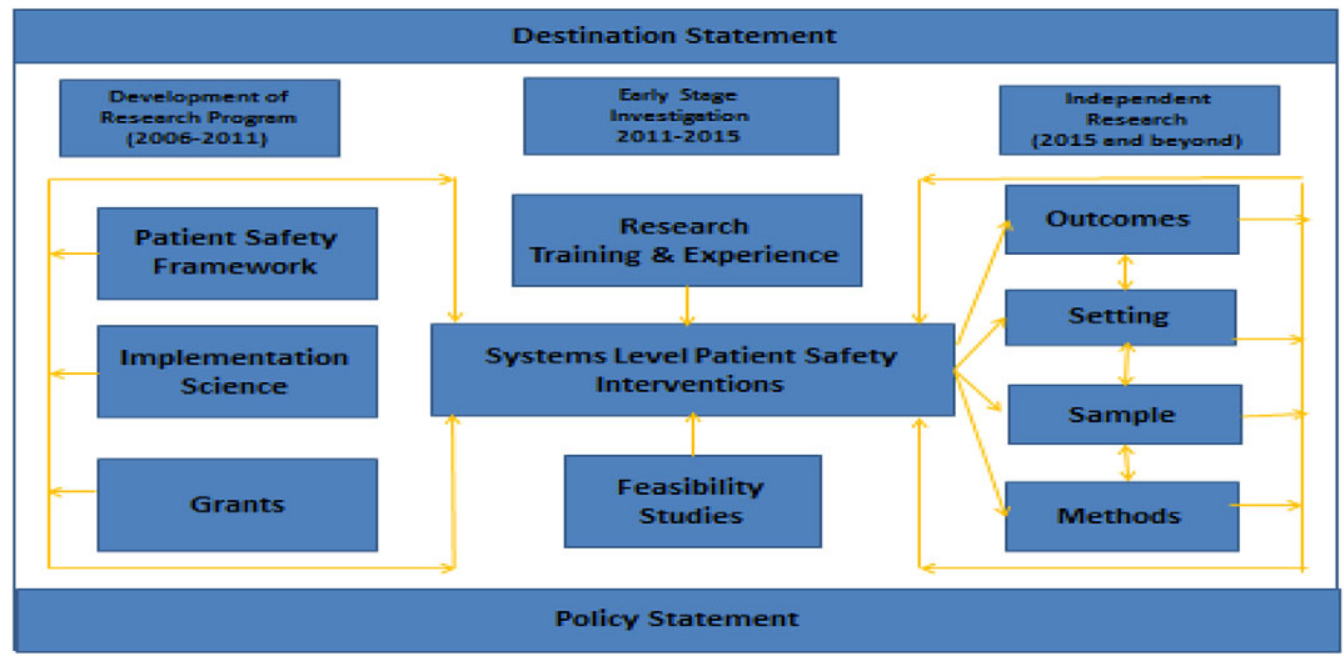

Figure 1. Skeleton of a research career cartography map focused on systems level patient safety outcomes.

of a hodgepodge of past research experiences and ideas for future projects without any indication of how these were all connected and what the end goal was. Again, I was disheartened to learn how difficult it was to display my long-term career goals. However, once I focused on my long-term goals, an iterative process began where I was able to fill in the "gaps" necessary to reach them. The process also included further refinements to my policy and destination statement until all components of the career cartography process coalesced (Figure 2). Additionally, I continued to seek feedback from peers not familiar with my area of interest and from my mentors until all components of the career cartography map made sense to everyone. I was so relieved to have a coherent career map to utilize to display my past research efforts, current projects, future plans, publications, and potential impact to science that I initially did not consider that this is a living, breathing document that will continue to change. After only one summer and an unfunded project, I found that I once again needed to revisit my career map to tweak my plan. This did not entail changing my destination statement, policy issues, or long-term goals but simply necessitated that I reconsider alternative pathways to achieve these long-term goals. While it is not without its challenges, I truly believe that this is something I could have started using while a graduate student to help frame my research goals and career.

\section{Case Scenario 3: From Abstract to Concrete (Putting It on Paper)}

Destination statement. Feetham and Doering (2015) emphasized the importance of the clarity of one's destination or end goal before undertaking any project or other scientific or professional development-related steps. In this sense, since my undergraduate studies, I knew I wanted to change individuals' lives and influence their health through scientific exploration and discoveries. Nursing became the ideal vessel through which to gain the necessary training and expertise to achieve this goal. During my studies, I continuously tackled my work with the understanding that I had to be working towards an endpoint, a health outcome, a scientific contribution.

Writing the destination statement was interesting as my peers and I debated about the difference between the "destination statement" and the "purpose of the program of research." As I came to understand the true definition of a destination statement (as described in Feetham $\delta$ Doering, 2015, pp. 2-3) I had to go back to the drawing board and figure out "what I am all about." Only through this self-reflective process was I able to conjure one sentence that describes my long-term contribution throughout my scientific journey. The destination statements continued to evolve throughout our regular meetings, as it needed to not only reflect my long-term goals but also convey those goals in a language that was clear enough to be understood by individuals whose training, work, and scientific vocabulary differed from mine.

From this process, I developed the following destination statement: "to optimize the health of low-wage workers who are experiencing and/or at risk for developing chronic health conditions." This statement is broad enough to allow me to contribute to the occupational health field in a variety of ways that will span my entire career. However, the statement is also specific enough to enable anyone to determine my line of work, population of interest, outcomes, and potential contributions. Regardless of its variation, the basis of this destination 


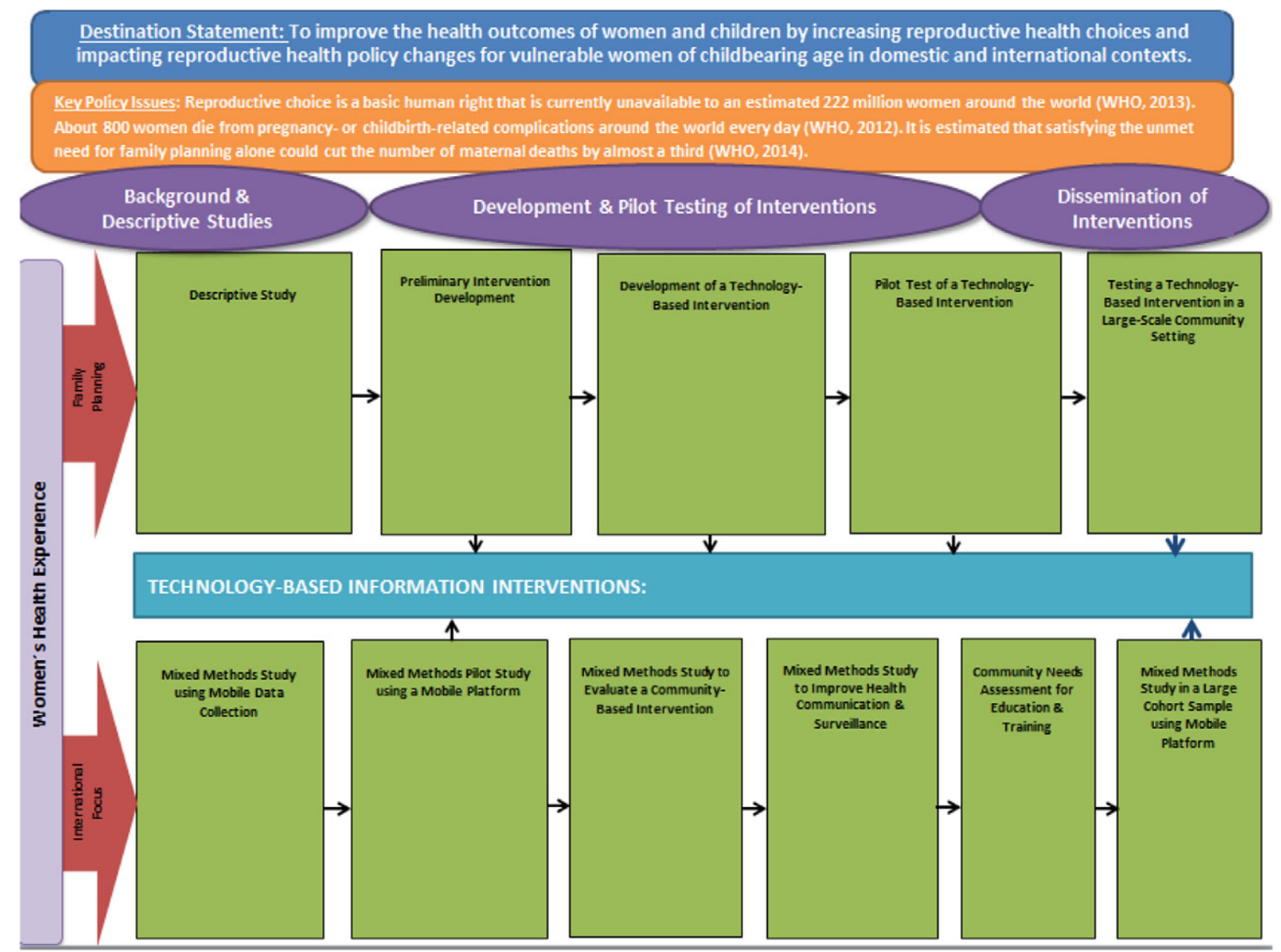

Figure 2. Skeleton of a global reproductive health career map.

statement will remain the same. I can focus on a specific group of low-wage workers (i.e., hotel housekeepers) or a specific health outcome.

Policy. My work focuses on systems and population level changes. Thus, connecting the work to a policy made sense. Regardless of whether interventions have an individual or systems focus, a connection with policy is likely to yield more sustained and effective changes. When a policy implication is involved, the issue at hand becomes a public health concern. Working through the career cartography process has enabled me to push beyond the individual health outcome and think about how my work will impact the world. My work has policy implications across various public health issues such as worker health, workplace improvement, vulnerable populations, toxic stressors, psychosocial stressors, and chronic conditions. An example of a policy relating to my work is the Affordable Care Act, which emphasizes the importance of using the workplace as a platform to promote worker health. Thinking about the career cartography process required me to grasp the need for transparency in my science as it relates to policy or system-level outcomes and clear communication with key stakeholders. Stakeholders may vary depending on the researcher's interests and program of research. For my work, stakeholders would include, but are not limited to, nurses, employers, employees, and federal entities that focus on workers' health such as the Occupational Safety and Health Administration.

Career map. To make sense of the skeleton for my career maps, I considered everything in chronological order, with the understanding that there will be ongoing projects to reach my end goal. It made sense to depict the projects, the rationale for how they relate to my long-term scientific career plan, and their funding source (Figure 3). However, I came to realize that like any other graphic, it is best to note what is most important with the least amount of wording possible.

The ideology behind my career map was influenced by my epistemology and ontological understandings 


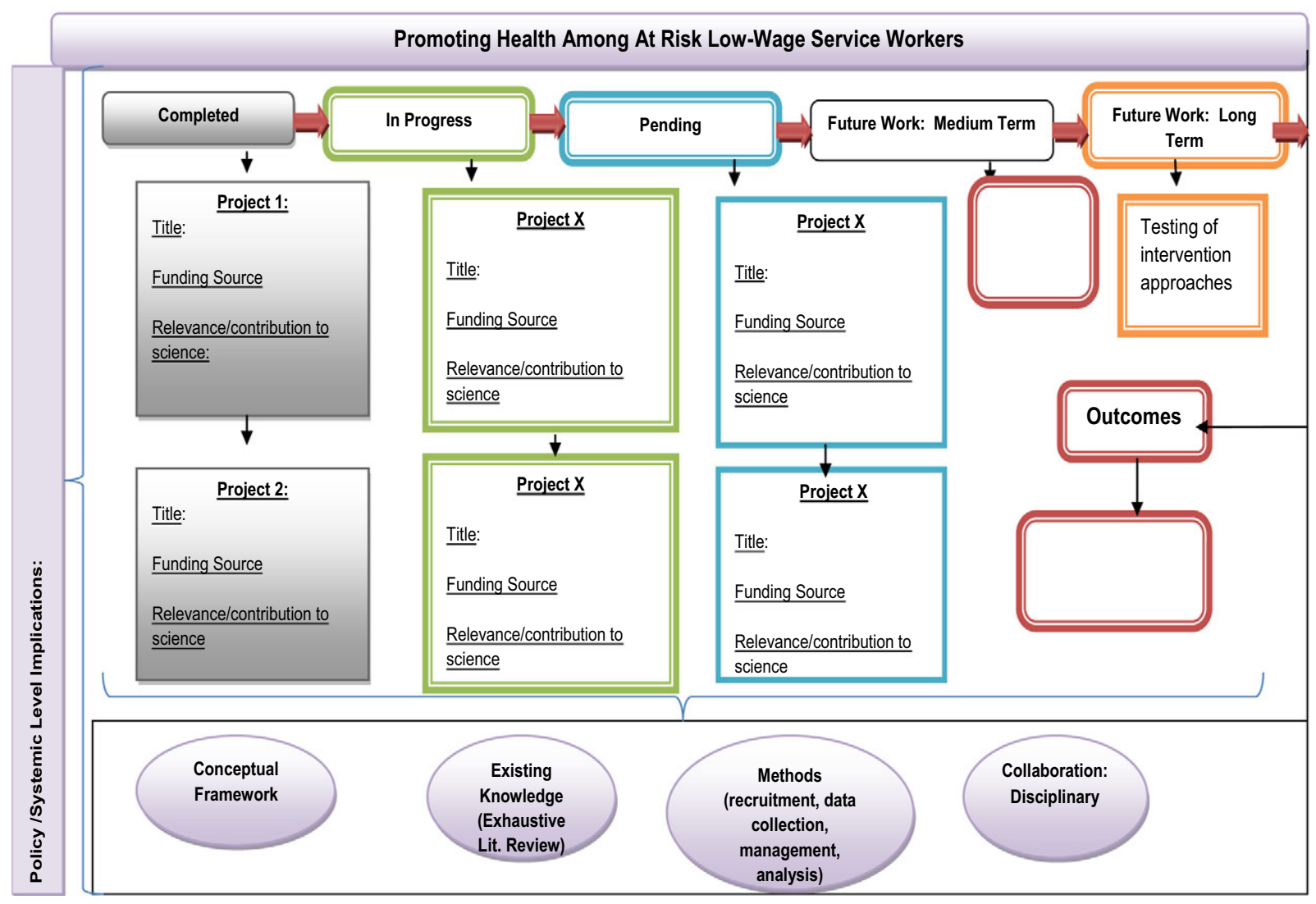

Figure 3. Skeleton of promoting health among at-risk low-wage service workers map.

of the world and what impacts individuals' health and well-being. Although the drawing of the map required much creativity and graphic skills, connecting the dots across research projects and the constant reference to the "endpoint" and the "so what question" proved to be more challenging and complex. Specifically, when drawing my career map I felt the need to differentiate the research projects and still show how they connect with my career progress. The terms "leadership" and "contribution" continued to resonate throughout my process. Having the guidance of Dr. Feetham and her work was instrumental in considering the development of my career cartography in sections: (a) writing a destination statement; (b) relating my work to current policies; and (c) putting everything together via a drawing that depicted the research, career progress, scientific contribution, and policy implications.

\section{Case Scenario 4: Looking Forward}

Destination statement. One of the most difficult aspects for me in creating a destination statement was thinking broadly and determining long-term goals for my program of research. I found that I was very comfortable with short-term goals but was not able to articulate and had little practice creating long-term goals. As such, I spent a significant amount of time reflecting on how my research trajectory would evolve. This involved reviewing other destination statements, discussing long-term goals with peers and faculty mentors, and rewriting the destination statement. It felt like a significant accomplishment to create a destination statement. Since there is not a right or wrong to the destination statement, I am looking forward to regularly reviewing and modifying the destination statement as my career advances.

Key policy issue. My career cartography process was developed within the context of cancer survivorship health policy, which focuses on both improving the quality of patient care as well as quality of life of individuals with cancer (National Coalition for Cancer Survivorship, 2017). Understanding policy (health, science, and public) and linking my program of research to it was another challenge for me. My research interest and program of research developed from my clinical practice as an oncology nurse and desire to improve the quality of life of patients. My formal education (undergraduate and graduate) did not include courses or seminars in policy, so 


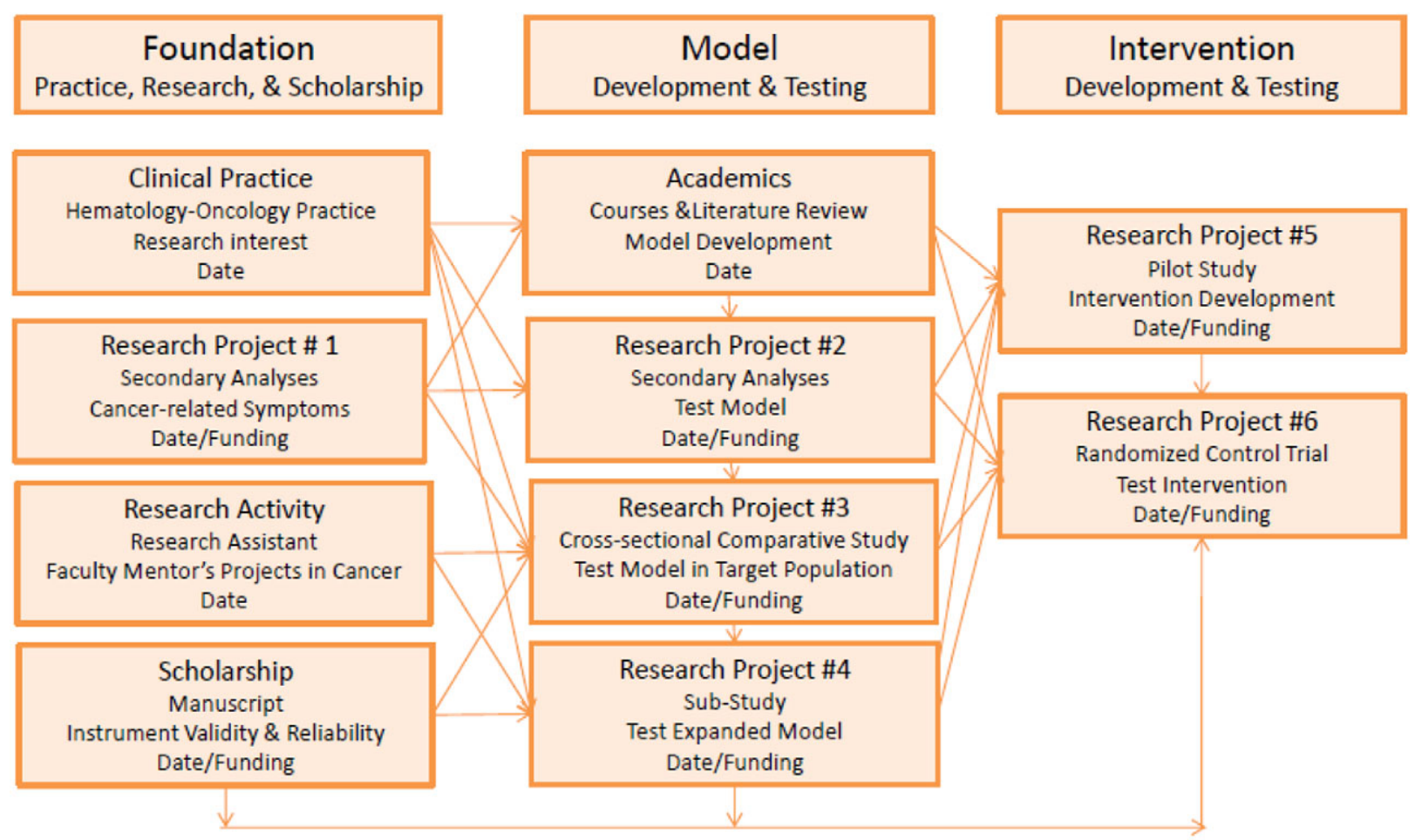

\section{Destination and Policy Statement}

Figure 4. Skeleton of promoting health and well-being of individuals with cancer map.

the challenge for me was to achieve a basic understanding of policy and identify key policy issues for cancer survivors. To do this, I started by talking with colleagues about their program of research and how health policy informed it. I subsequently identified cancer-related health policy coalitions, read their position statements, and reflected on my program of research. Looking forward, I feel I need further education and hands-on experience with health and public policy so that my program of research can make a meaningful contribution to the health of cancer survivors. I am currently looking at furthering my policy education through course work, programs, and special interest groups.

Career map. There were many iterations of my career map (Figure 4). The first map included only boxes with main research projects and research-related activities but no direction or flow. It also lacked details about the activities, why it was important, and the outcomes. Over time, I began to identify patterns in my experiences and group these experiences into broad themes, including (a) practice and research-related activities that were building blocks for my program of research, (b) activities related to model development and testing, and (c) activities related to intervention development and testing. Additionally, I began to include information about the type of study or activity, dates, and sources or potential sources of funding. The feedback from my postdoctoral colleagues was a main part of the process. It was a rewarding process and I enjoyed seeing my work mapped out. The process and the product also helped me see gaps in my research and allowed me to work with my research mentors to develop training goals for my postdoctoral fellowship and identify learning activities to achieve those training goals.

\section{Lessons Learned}

The creation of a career map is heavily dependent on effective implementation of the career cartography process. Feetham and Doering (2015) identified the career cartography process to be inclusive of the following components: a destination statement, the policy context, and the depiction of the actual career map. During the experience of creating career maps, the authors recognized that the cartography process had additional features beyond a supportive team that were critical to successfully crafting a career map in a timely manner. The authors have 
identified seven "lessons learned" that we encourage others to consider if they embark on the cartography process.

\section{Supportive Mentoring Team}

As mentioned in the introduction, having a supportive mentoring team is necessary for nurse researchers to have the guidance and feedback in order to develop clear and succinct career cartography. In each of our case scenarios, we discussed the importance of having the mentorship of a team of people including content experts, process experts (including Dr. Feetham), and peer support, which in our case included our career cartography support team. The supportive career cartography team serves the purpose of developing an individual's career as well as advancing science and supporting the continued growth of the nursing profession (Byrne \& Keefe, 2002). We were members of a postdoctoral group that adopted the process of career cartography with the creation of career maps as a main objective. Our group routinely met to review each other's work and share experiences. The homogeneity in rank of our group members affirmed the common urgent task to define and design a research path that would maximize the tenure of the postdoctoral contract, which led to a reduction in fears of vulnerability. In addition, each of us had a network of other supporters that included content and process experts, nursing leaders that understood the steps needed to launch a successful research career, and an expert in the process of creating the career maps (Dr. Feetham). Faculty members across all ranks shared experiences and exchanged ideas on what works and what does not. Faculty mentors from outside the School of Nursing also provided additional mentorship and expertise throughout the career cartography process

\section{Start Early and Reflect Regularly}

We learned it is important to start early and reflect regularly. In fact, when reflecting on the career cartography process, all of us wished it was something we would have started when we were doctoral students. We concluded that it was important to take the time to think about and reflect on our personal and career goals throughout the academic process, including while we were in school and throughout our career. Knowing our goals and getting started on our career cartography early in our careers helped us to be thoughtful about our next steps. We also sought opportunities to gain experiences in areas to advance our clinical practice or program of research. Starting this process early also allowed us time to make meaningful contributions to nursing and the health of the public. Seeking out others interested in career cartography and creating a supportive group to encourage collaborations during the career cartography process were keys to our group.

\section{Be Brief and to the Point}

It is essential that the career maps are brief and to the point. We found that our career maps are documents that we share with colleagues, mentors, and supervisors. It is therefore important to keep them short (ideally one page) and clear. We also found that we were developing different maps to convey different career components such as research outcomes, funding, or teaching. We recognized that we all wanted to include everything in our career cartography process, but it is important to include only what is salient. This led us to start the career cartography process by including all the information we thought was necessary, and then we worked on analyzing and editing it. For every piece of information included, we also asked ourselves if it was important and why. If it was not important, then we removed it.

\section{Keep It Simple and Avoid Jargon}

As noted during our case scenarios, many of us started with career maps loaded with jargon that no one else could understand. We quickly recognized that if we are the only ones who understand our career map, then we are limiting its reach. As such, we determined it was important to evaluate our destination statements, policy statements, and career maps for context-specific jargon and remove it. Sharing our career maps with others was another important method for identifying jargon, gaps, and novel paths to advancement.

\section{Be Open to Change}

It was extremely difficult to prevent being attached to our career maps. It was a painful process to remove information or edit it. This document is an outline of our career goals and passions. However, we found it was necessary to be open to change and to not get too attached. It was also necessary to have a safe space to share the drafts of our career maps with a supportive group. Often the map may have seemed clear but to a colleague the map was vague or overly ambitious. Thus, we finally came to terms with the fact that we must be willing to make changes during the career cartography process in order to help improve our final product. Letting others see our work also served to inspire us and bring fresh perspectives about ways to highlight the practice, teaching, and research contributions we have made. 


\section{Make Time}

One major barrier to completing the cartography process for our group was time constraints. As we previously alluded to, junior faculty are often struggling to juggle a number of commitments and often do not have the time to devote to professional growth. The career cartography process is usually not required for a job. It is a personal journey, which required us to set aside time to create. However, we strongly believe that nurses must make time to outline their career goals in a comprehensive manner in order to fuel personal and professional growth.

\section{Focus on the Overall Career Destination}

We continually asked ourselves, "Where do we want to be at the end?" We used the process of starting with our destination statement and then mapped out our research projects, work goals, and future accomplishments starting backwards from our future goals. This helped us determine exactly what steps were necessary to achieve those goals. It was important to focus on the overall career destination.

Utilizing the career cartography process has provided us the opportunity to look at the bigger picture. We were able to reflect on what we have accomplished thus far, where we wanted to go, and what will be the level of impact of our work. It has also enabled us to become more attuned with the current policies that speak to our work and the public health needs both on a national and international level. Although this article reflects only the research aspects of our careers, the career cartography framework also helped generate conversations about the type of service we will be involved in, the type of courses we will be teaching, and the method in which we will approach all of the important components of an academic career.

\section{Conclusions}

The purpose of this article was to show how four early-career nurse researchers concretely applied the career cartography framework to develop their research career paths. Each of us, as nurse researchers, has taken a slightly different approach to utilize the career cartography process to develop our career maps as exhibited through our case scenarios. Regardless of the differences in our approaches, research interests, and health outcomes, what became clear among the four cases is the importance of the "so what." Using the visual depiction of the career map allowed us to articulate our scholarship trajectory with our peers, mentors, department heads, the Dean, and colleagues across our discipline. The supportive mentoring team proved to be very critical to move us through the career cartography process in a timely manner, validating Feething and Doering's (2015) work.

We agreed that creating the career maps using the career cartography process gave us the organization, confidence, and ability to assert ourselves as nurse scientists with important research trajectories. Unfortunately, nurses tend to undersell themselves. Components of career cartography can be applied across all areas of nursing (Hinds et al., 2015). The career cartography process allows nurses to visually depict their contributions to science and to appreciate their value in nursing and health of the public. As in the hospital setting, nurses must remember that their work is never done. As noted by Feetham and Doering (2015), "there is neither a right map, nor are maps ever finished" (p. 73). Thus, the career cartography process and the visual depiction of the career map must be a malleable document that evolves with nurses as their careers grow and change.

\section{Acknowledgments}

We are greatly indebted to Dr. J. J. Doering for her insightful contributions to our manuscript.

\section{Clinical Resources}

- Career cartography: A conceptualization of career development to advance health and policy: https://www.ncbi.nlm.nih.gov/pubmed/25154922

- Career mapping: Developing nurse leaders, reinvigorating careers: https://www.ncbi.nlm.nih.gov/ pubmed/19820525

- Essentials of building a career in nursing research: https://www.ncbi.nlm.nih.gov/pubmed/ 27424961

- Living on Purpose: http://www.living-on-purpose. net/finding-your-true-purpose/personal-legacy

- Learning by Shipping: https://blog.learning byshipping.com/2013/03/28/defining-yourcareer-path-journey-or-destination/

- Professional excellence and career advancement in nursing: A conceptual framework for clinical leadership development: https://www.ncbi.nlm.nih. gov/pubmed/22157789

\section{References}

Beck, M. (2008). Finding your own north star: Claiming the life you were meant to live. New York, NY: Three Rivers Press. 
Bensing, J. M., Caris-Verhallen, W. M., Dekker, J., Delnoij, D. M., \& Groenewegen, P. P. (2003). Doing the right thing and doing it right: Toward a framework for assessing the policy relevance of health services research. International Journal of Technology Assessment in Health Care, 19(4), 604-612. doi:10.1017/S0266462303000564

Boyden, K. M. (2000). Development of new faculty in higher education. Journal of Professional Nursing, 16(2), 104-111.

Brody, A. A., Edelman, L., Siegel, E. O., Foster, V., Bailey, D. E. Jr., Leak Bryant, A., \& Bond, S. (2016). Evaluation of a peer mentoring program for early career gerontological nursing faculty and its potential for application to other fields in nursing and health sciences. Nursing Outlook, 64(4), 332-338. doi:10.1016/j.outlook.2016.03.004

Byrne, M. W., \& Keefe, M. R. (2002). Building research competence in nursing through mentoring. Journal of Nursing Scholarship, 34(4), 391-396. doi:10.1111/j. 1547-5069.2002.00391.x

Drummond-Young, M., Brown, B., Noesgaard, C., Lunyk-Child, O., Maich, N. M., Mines, C., \& Linton, J. (2010). A comprehensive faculty development model for nursing education. Journal of Professional Nursing, 26(3), 152-161. doi:10.1016/j.profnurs.2009.04.004

Elsbach, K. D. (2003). How to pitch a brilliant idea. Harvard Business Review, 81(9), 117-123.

Feetham, S., \& Doering, J. J. (2015). Career cartography: A conceptualization of career development to advance health and policy. Journal of Nursing Scholarship, 47(1), 70-77. doi:10.1111/jnu.12103

Feetham, S. L. (2011). The role of science policy in programs of research and scholarship. In A. S. Hinshaw \& P. A. Grady (Eds.), Shaping health policy through nursing research (pp. 53-71). New York: Springer.

Green, H. G. (2009). Destination statement: Getting from here to where you want to go. Retrieved from http://thehumanfactor. biz/wordpress/wp-content/uploads/2009/07/1209-smartpeople-destination-statement.pdf

Hader, R. (2005). Career mapping: Chart a course for your future. Nursing Management, 36(10), 4.

Hinds, P. S., Britton, D. R., Coleman, L., Engh, E., Humbel, T. K., Keller, S., \& Walczak, D. (2015). Creating a career legacy map to help assure meaningful work in nursing. Nursing Outlook, 63(2), 211-218. doi:10.1016/j.outlook.2014.08.002

Hofler, L., \& Thomas, K. (2016). Transition of new graduate nurses to the workforce: Challenges and solutions in the changing health care environment. North Carolina Medical Journal, 77(2), 133-136. doi:10.18043/ncm.77.2.133

Kasprzak, L. (2014). Build your brand for positive career impact. Chemical Engineering Progress, 110(4), 25.

Messmer, M. (2003). Career mapping: Charting an employee's path to success. Strategic Finance, 85(6), 1-2.

National Coalition for Cancer Survivorship. (2017). What is public policy and how does it impact cancer care? Retrieved from http://www.canceradvocacy.org/cancer-policy/whatis-public-policy/

Nies, M. A., \& Troutman-Jordan, M. (2012). Mentoring nurse scientists to meet nursing faculty workforce needs. Scientific World Journal, 2012, Article 345085. doi:10.1100/2012/345085

Shirey, M. R. (2013). Leaning in: Lessons for leadership career development. Journal of Nursing Administration, 43(11), 562-565. doi:10.1097/01.NNA.0000434513.20115.46

Tin, S. S., \& Wiwanitkit, V. (2015). Career legacy map. Nursing Outlook, 63, 109. doi:10.1016/j.outlook.2014.10.002

Trostle, J., Bronfman, M., \& Langer, A. (1999). How do researchers influence decision-makers? Case studies of Mexican policies. Health Policy and Planning, 14(2), 103-114

U.S. Department of Health and Human Services, Office of Disease Prevention and Health Promotion. (n.d.). Healthy People 2020. Washington, DC: Author. Retrieved from https://www.healthypeople.gov/2020/ about/foundation-health-measures/Determinantsof-Health

van Eck Peluchette, J. V. E., \& Jeanquart, S. (2000). Professionals' use of different mentor sources at various career stages: Implications for career success. Journal of Social Psychology, 140(5), 549-564. doi:10.1080/ 00224540009600495

Villarruel, A. M., \& Fairman, J. A. (2015). The Council for the Advancement of Nursing Science, Idea Festival advisory committee: Good ideas that need to go further. Nursing Outlook, 63(4), 436-438. doi:10.1016/j.outlook. 2015.04 .003

Violence Against Women Reauthorization Act of 2013. (2014). Pub. L. No. 113-4. Retrieved from https://www. congress.gov/bill/113th-congress/senate-bill/47/all-info

Wills, C. E., \& Kaiser, L. (2012). Navigating the course of scholarly productivity: The protégé's role in mentoring. Nursing Outlook, 50, 61-66. doi:10.1067/mno.2002. 122429 